\title{
APROXIMACIÓN CONCEPTUAL Y CRÍTICA AL NEOCONSTITUCIONALISMO*
}

\author{
Eduardo Aldunate Lizana**
}

\begin{abstract}
RESUMEN
En el presente trabajo se examinan las distintas acepciones que se pueden distinguir para el uso del término neoconstitucionalismo, y se enfrentan de manera crítica algunos de sus principales postulados.
\end{abstract}

\section{NEOCONSTITUCIONALISMO - DERECHO CONSTITUCIONAL - TEORÍA CONSTITUCIONAL}

\section{A conceptual and critical approach towards neo-constitutionalism}

\begin{abstract}
In the following paper, different distinguishable meanings for the term neo-constitutionalism are examined and some of its most important assumptions are faced critically.
\end{abstract}

\section{NEO-CONSTITUTIONALISM - CONSTITUTIONAL LAW - CONSTITUTIONAL THEORY}

* Artículo desarrollado en el marco del proyecto Fondecyt No 1090424, Neoconstitucionalismo: análisis y crítica de un modelo teórico y la posibilidad de su aplicación para el fortalecimiento del sistema constitucional chileno, del cual el autor es su investigador responsable.

** Abogado, Doctor en Derecho, Profesor de derecho constitucional e interpretación jurídica en la Facultad de Derecho de la Pontificia Universidad Católica de Valparaíso, Valparaíso, Chile. ealdunat@ ucv.cl

Artículo recibido el 25 de marzo de 2010 y aceptado para su publicación por el Comité Editorial el 28 de mayo de 2010 . 

término neoconstitucionalismo es uno cuyo uso se remonta, a más tardar, a la década de los 70 del siglo pasado. Ya avanzado el camino hacia sus bodas de oro no existe claridad respecto del objeto al cual se hace referencia con esta denominación. El objeto de este trabajo es presentar el resultado de un encuentro con el neoconstitucionalismo, lo que implica dos cosas. La primera, un acercamiento e intento de precisar sus contornos, su entidad y su identidad; la segunda, una toma de posición, un enfrentamiento preliminar con el resultado de este encuentro.

\section{1. ¿ES EL NEOCONSTITUCIONALISMO UN NUEVO CONSTITUCIONALISMO?}

El neoconstitucionalismo, como sucede con otras construcciones similares, es un neologismo conformado por un referente conocido y la adjetivación de un elemento temporal de actualización. En esta estructura, el neoconstitucionalismo sería un constitucionalismo nuevo. Sin embargo, en el análisis, esta posibilidad de construcción semántica es descartada tempranamente. El Constitucionalismo, como fenómeno social, político y jurídico originado a fines del siglo XVIII y primer tercio del siglo XIX, tiene unos contornos bien precisos; se trata, en primera línea, de un movimiento político, con inspiración filosófica ilustrada que, sobre la base del cuestionamiento de los criterios de legitimación tradicional, busca dotar al poder de un fundamento de legitimidad racional, tanto desde el punto de vista de su forma -la ordenación articulada y sistemática de los fundamentos de la organización política en un solo instrumento-, como desde el punto de vista de su origen -una ordenación objeto de una decisión consciente y deliberada del cuerpo político o sus representantes-, así como desde la perspectiva de su contenido -la consagración de un régimen de limitación del poder a través de la sujeción de las autoridades a la constitución y a las leyes, de la división del poder en distintos poderes separados y de la declaración de los derechos individuales. Dicho de otra manera, el Constitucionalismo persigue que los Estados se doten de constituciones, entendidas de la manera señalada. Puede considerarse un verdadero programa político, basado en unos postulados filosófico-políticos y jurídicos, y que permite, a sus adherentes, identificarse nominativamente con la denominación.

Si se aplica el prefijo "neo" a este contenido, podría pensarse que el neoconstitucionalismo es un resurgimiento de los postulados del constitucionalismo, o bien un constitucionalismo de nuevo cuño. Para ello, y con independencia de su contenido, tendría que conservar al menos este carácter de programa dirigido a la forma de organizar el poder, a sus criterios de legitimación y a la relación entre éstos y el derecho.

Nada de ello ocurre, sin embargo, en el caso del término en análisis. No describe un movimiento como programa político o unos objetivos políticos a los cuales pueda adherir alguien que se declara "neoconstitucionalista", sino que, en primera línea, se usa para describir ciertos fenómenos o prácticas institucionales de los Estados constitucionales -en su inicio, europeos- tras la Segunda Guerra Mundial.

Dos elementos parecen estar a la base de esta evolución; uno de ellos histórico cultural, y el otro, de tipo institucional. El primero es el impacto que en la cultura 
jurídica europea tuvo la Segunda Guerra Mundial, a partir de la experiencia de la ausente capacidad de un derecho concebido esencialmente como acto o decisión de voluntad puesta a regir para contener las atrocidades de un poder político totalitario, beligerante y genocida. Frente a este fracaso del derecho, sino producto, al menos alimentado por una determinada forma de concebirlo desde algunas vertientes del positivismo jurídico, resulta comprensible que la mirada se vuelva a actos de habla que devuelven la esperanza de que el derecho pueda contener a la política: reaparece, aquí, el recurso a los valores en el discurso jurídico ${ }^{1}$. Pero no en todo el discurso jurídico, sino que específicamente en el discurso jurídico constitucional, de la mano del segundo elemento. Éste es la instauración (justamente en Alemania e Italia, dos países que, desde una brillante tradición cultural y humanista, habían derrapado a regímenes totalitarios) de órganos de jurisdicción constitucional dotados de importantes competencias, algunas de las cuales, en especial en el caso alemán, obligaban a la respectiva magistratura a imbricar el texto constitucional en el razonamiento para las resoluciones de cuestiones ya no políticoconstitucionales, sino que del contencioso ordinario de los tribunales.

Este punto no ha sido destacado en el análisis de las elucubraciones teóricas tras la Segunda Guerra Mundial, el hecho de que a) estamos ante un conjunto de juristas, i. pertenecientes a la comunidad nacional que carga en sus espaldas la experiencia de una dictadura totalitaria, el sentimiento de culpa por la guerra y por el genocidio, ii. bajo la mirada atenta de fuerzas de ocupación (o equivalentes), b) que se ve llamado a resolver cuestiones i. para las cuales no existe un método previamente desarrollado o aplicado, ii. sobre la base de un texto sucinto -en contraposición a la tarea tradicional de los juristas, dirigida a cuerpos normativos de mayor densidad textual-y iii. aplicado, al menos en el caso de la queja constitucional alemana incluso a cuestiones contenciosas entre particulares.

Si a esto agregamos que en la literatura alemana de entreguerras ya se había desarrollado, en la obra de Rudolf Smend, una teoría de la constitución en la cual una de sus funciones se describía como la de integración espiritual en torno a los valores de los que daban cuenta los derechos fundamentales, resulta a la mano entender el por qué, a muy poco andar de su funcionamiento, el Tribunal Constitucional Federal alemán afirma la función de los preceptos sobre derechos fundamentales, no en una dimensión normativa tradicional, sino que en una sustancialización ontológica; los enunciados sobre derechos fundamentales dejan de constituir la base para fundar reglas de deber ser y pasan a considerarse un orden objetivo de valores. Si bien es cierto que con ello los

${ }^{1}$ Y no sólo el discurso jurídico, sino que en la cultura en general. En el estudio que precede a la traducción en castellano de "Star Trek y los derechos humanos", de Robert Alexy, Alfonso García Figueroa relata cómo, mientras en inglés y en la traducción al castellano de un diálogo de la popular serie Star Trek (episodio 35 de Next Generation, The measure of a man) "She may overly attached to the letter of the law, but I suspect she still understands its spirit" se conserva la contraposición entre letra de la ley y espíritu, en alemán la traducción opone, a la letra de la ley, algún grado de humanidad en el juez (en este caso, quien juzgaba era la teniente Luovois). El texto de la fuente positiva no se enfrenta, en esta traducción, a otra categoría técnica -el espíritu de la ley-sino que a una referencia elemental: la condición de humanidad -metajurídica, si se quiere- del juzgador. 
derechos fundamentales se mantienen en el universo de las categorías deónticas, no lo es menos que, desde la perspectiva de la función que cumplen los textos normativos en el sistema de fuentes, se presencia aquí una revolución copernicana, si es que la figura es aplicable a la cultura jurídica: los textos normativos no serán más considerados como un llamado al juez a disciplinar su proceso argumental en la construcción de reglas, sino que como definiciones de lo valioso, que, una vez asumidas como tales, dejan en libertad de acción al juzgador.

Es en este punto donde se puede establecer un criterio para distinguir aquello que puede calificarse como evolución del constitucionalismo en el siglo XX y tras la Segunda Guerra Mundial, de aquello que ha venido en llamarse neoconstitucionalismo. Este último implica una actitud que selecciona determinados aspectos de dicha evolución (en especial aspectos que dependen de ciertas prácticas de los operadores jurídicos y de la influencia que la doctrina ejerce sobre ellos) y los valora favorablemente.

Junto con la evolución constitucional occidental en general, el específico proceso de integración europea, tanto en las demandas hacia el sistema institucional de sus países miembros y el de la propia integración, como en los desafíos y posibilidades que abre a la reflexión desde la ciencia jurídica, constituye un elemento adicional dentro del cúmulo de factores que se suelen incorporar dentro de aquello que se nombra como neoconstitucionalismo, si bien, como se apreciará a lo largo de este trabajo, este es un tema que plantea problemas distintos que aquellos generalmente tratados bajo la etiqueta de neoconstitucionalismo y que se distinguen por plantearse, como tales problemas, a la teoría de la constitución en general, y no depender de determinadas prácticas institucionales o enfoques doctrinales. La denominación de pluralismo constitucional, propuesta por Núñez ${ }^{2}$, u otras similares, pueden servir para separar terminológicamente esta cuestión de aquellas que se ubican bajo la genérica alusión al neoconstitucionalismo.

No está de más aprovechar la oportunidad para destacar que, cuando se habla de neoconstitucionalismo, no se alude, ni lejanamente, a un fenómeno de alcance universal. La evolución constitucional del mundo anglosajón no se ha visto significativamente afectada ni por el diseño ni por las características de la evolución jurisprudencial y doctrinaria apreciada en Europa continental y Latinoamérica. Pueden encontrarse puntos de encuentro (por ejemplo, la reflexión sobre la relación entre derecho y moral) en autores de diverso origen; pero los elementos que en su conjunto (y no aisladamente) se vinculan al neoconstitucionalismo se despliegan como un fenómeno esencialmente europeo-continental y latinoamericano.

\section{SENTIDOS DEL TÉRMINO NEOCONSTITUCIONALISMO}

La primera referencia acreditable, entonces, de la voz neoconstitucionalismo, consiste en la descripción de un conjunto de características del diseño y de la práctica constitucional

${ }^{2}$ Núñez, M., "Una introducción al constitucionalismo posmoderno y al pluralismo constitucional”, en Revista Chilena de Derecho, Pontificia Universidad Católica de Chile, Vol. No 31, N 1, pp. 115-136. 
posterior a la Segunda Guerra Mundial. Autores que pueden considerarse al interior del neoconstitucionalismo, apreciado como movimiento o tendencia (que se tratará más adelante), describen este sentido del término como aludiendo a "una serie de fenómenos evolutivos que han tenido evidentes impactos en lo que se ha llamado el paradigma del Estado constitucional"3.

El inventario de estos fenómenos es extenso y no necesariamente compartido por todos los autores que podrían mencionarse de manera preliminar como cercanos a posturas del neoconstitucionalismo. Adicionalmente, debe mencionarse que se trata en lo esencial de lecturas de fenómenos, ocasionalmente imprecisas e incluso erradas, y que en su conjunto pueden llegar a apreciarse como incompatibles. Cabe adelantar aquí que uno de los problemas que plantea el término en estudio es que no se articula dentro de un órgano o cuerpo de postulados sistemáticos, ni siquiera en lo que podría considerarse su función descriptiva de las realidades constitucionales de la segunda mitad del siglo XX. Estos fenómenos, sin entrar todavía en su análisis, e incluyendo categorías que son parcialmente cosecantes, son los siguientes:

a) cambio del estado legislativo de derecho al estado constitucional de derecho (paso al constitucionalismo rígido), entendido éste como un estado de constitución rígida y control de constitucionalidad de leyes ordinarias ${ }^{4}$ (o bien: constitución rígida y su garantía jurisdiccional $)^{5}$;

b) constituciones con alta densidad normativa o alto contenido normativo ${ }^{6}$, dado esencialmente por la inclusión del catálogo de derechos fundamentales y de principios rectores de la organización política, social y económica;

c) constituciones con fuerza normativa vinculante y aplicación directa en el sistema de fuentes, con el consiguiente resultado de irradiación (de la constitución hacia las demás fuentes) y de “constitucionalización” del derecho, cuando los tribunales asumen ambos postulados ${ }^{7}$;

d) consideración de los derechos fundamentales y eventualmente de otras partes del texto constitucional como "valores" en la argumentación fundante de decisiones jurisdiccionales, en especial, pero no exclusivamente, a nivel de la jurisdicción constitucional ${ }^{8}$;

3 Carbonell, M., "Nuevos tiempos para el constitucionalismo”, en Carbonell, M. (coord.), Neoconstitucionalismo(s), Trotta, Madrid, 2003, pp. 9-10.

${ }^{4}$ Ferrajoli, L., "Pasado y futuro del Estado de derecho", en Carbonell, M. (coord.), Neoconstitucionalismo(s), Trotta, Madrid, pp. 14, 18.

${ }^{5}$ Prieto, L., "Voz Neoconstitucionalismo", en Carbonell M. (coord.), Diccionario de Derecho Constitucional, Porrúa y Universidad Autónoma de México, México, 2005, pp. 420 a 423, citado por Olano, H., Interpretación y neoconstitucionalismo, Porrúa e Instituto Mexicano de Derecho Procesal Constitucional, México, 2006, p. 29.

6 Prieto, L., "Voz...", cit.

7 Guastini, R., “La 'constitucionalización' del ordenamiento jurídico: el caso italiano”, en Carbonell, M. (coord.), Neoconstitucionalismo(s), Trotta, Madrid, 2003, pp. 49 y ss.

${ }^{8}$ Por todos, e inicialmente, fallo Lüth del Tribunal Constitucional Federal alemán. 
e) introducción del "método" de ponderación para la solución de conflictos entre derechos fundamentales o entre derechos fundamentales y otros principios constitucionales (en general, proposición de la ponderación como forma de solucionar la colisión entre valores). Al igual que en el literal precedente, en especial, pero no exclusivamente, a nivel de la jurisdicción constitucional;

f) específicamente en el ámbito europeo, el proceso hacia una mayor complejidad del sistema de fuentes y la relativización del rol de la constitución y el proceso político nacional frente al derecho europeo y el proceso de integración europea (como ya se ha señalado, este rasgo presenta características propias que ameritan su separación del grupo bajo estudio).

La doctrina, por su parte, ha tomado nota y posición respecto de los hitos de esta evolución. En parte importante, la reacción ha sido favorable a los mismos. Es en este ambiente laudatorio y propiciatorio de las características del diseño y de la práctica constitucional posterior a la Segunda Guerra Mundial donde puede ubicarse la segunda referencia de la voz neoconstitucionalismo. Carbonell, a continuación de la cita transcrita, señala que "con el término neoconstitucionalismo se hace referencia también a una determinada teoría del derecho que propugnado en el pasado reciente por esos cambios y/o que da cuenta de ellos, normalmente en términos bastante positivos o incluso elogiosos" 9 . Puede dejarse en suspenso el examen de la afirmación de que el neoconstitucionalismo constituye una nueva teoría del derecho (aun cuando pueda comprender diversos elementos o tomas de posición en el plano teórico); lo que interesa de la cita de Carbonell es el sentido del término en análisis como una actitud de satisfacción y apoyo a la evolución de la realidad constitucional de la segunda mitad del siglo XX. Paolo Comanducci utiliza la expresión "neoconstitucionalismo ideológico" para referirse al corpus doctrinal que no se limita "... a describir los logros del proceso de constitucionalización, sino que los valora positivamente y propugna su defensa y ampliación" ${ }^{10}$. Esta actitud, traducida al plano de la reflexión relativa al derecho, lleva a la elaboración y desarrollo del material institucional y, en algunos casos, a una postura militante proclive a determinadas opciones doctrinales, parcialmente coincidentes con, o que apuntan a profundizar en, los rasgos de la evolución institucional ya reseñados. Se pueden mencionar como manifestaciones de esta actitud,

a) una postura autorreflexiva respecto de algo denominado neoconstitucionalismo, que sería aquella teoría del derecho que aspira a describir los logros de la constitucionalización post Segunda Guerra Mundial ${ }^{11}$, teoría que se sitúa en un posible trasfondo iusnaturalista, pero, en todo caso, opuesta al iuspositivismo ${ }^{12}$, y

\footnotetext{
${ }^{9}$ Carbonell, M., "Nuevos tiempos...", cit., p. 10.

${ }^{10}$ Comanducci, P., "Formas de (Neo)Constitucionalismo: un análisis metateórico", en Carbonell, M. (coord.), Neoconstitucionalismo(s), Trotta, Madrid, 2003, p. 85.

${ }^{11}$ Comanducci, P., "Formas de (Neo)Constitucionalismo..., cit., p. 83.

${ }^{12}$ Comanducci, P., "Formas de (Neo)Constitucionalismo...", cit., p. 82.
} 
que reivindica una estrecha conexión entre derecho y moral, en especial a partir de la calificación de los derechos fundamentales como valores;

b) la recepción, tout court y ocasionalmente sin discriminar entre sus diversas variantes, de la idea del efecto horizontal de los derechos fundamentales, y

c) la defensa del "método" de la ponderación para la solución de conflictos entre derechos y/o principios constitucionales, entendida como la forma adecuada de enfrentar las particularidades de la interpretación constitucional y, en general, de la argumentación fundante de la aplicación de la constitución.

La identificación de los autores asociados al neoconstitucionalismo es doblemente difícil; en primer lugar, porque no está claro lo que sea el neoconstitucionalismo; en segundo lugar, porque los autores vinculados a esta corriente no se presentan, usualmente, como neoconstitucionalistas, ni es siempre posible establecer su posición respecto de los tópicos -neoconstitucionalistas- que tratan ${ }^{13}$. No obstante ello, es posible citar algunos nombres, a partir de la referencia que hace uno de los difusores más conspicuos del término, Miguel Carbonell. Carbonell identifica al neoconstitucionalismo como un fenómeno reciente en el ámbito de la cultura jurídica española e italiana, y en diversos países latinoamericanos ${ }^{14}$. Menciona Carbonell los aportes de Ronald Dworkin, Robert Alexy, Gustavo Zagrebelsky, Carlos Nino, Luis Prieto Sanchís y Luigi Ferrajoli. Más allá de estas referencias, se ocupan de tópicos relacionados, ocasionalmente desde una perspectiva crítica, Juan José Moreso, Paolo Comanducci, Alexei Julio Estrada, Riccardo Guastini, Alfonso García Figueroa, y otros. La frecuente referencia, en los textos que se pueden adscribir a esta corriente, a la obra del alemán Peter Häberle justificaría, también, incorporarlo entre estos autores.

Es interesante mencionar aquí que la evolución de la que hablamos se da fundamentalmente en el ámbito de influencia del diseño constitucional, la teoría y la práctica de Alemania e Italia. Las obras de los autores más influyentes, en sus respectivas traducciones al castellano o al portugués, reciben luego acogida en el espacio hispano-lusoamericano. Este dato no es irrelevante: mientras que autores de la importancia de Robert Alexy, o de la popularidad de Peter Häberle, traducidos al castellano, campean sin competidores sustantivos en la arena doctrinaria hispanoparlante, la crítica doméstica de origen a los mismos no suele ser traducida, proyectando de este modo una imagen de ellos de mayor autoridad o tamaño intelectual entre las huestes doctrinarias relativamente más pobres de los países receptores.

Por último, es posible encontrar el término neoconstitucionalismo aplicado a un nuevo "modelo", "paradigma" o teoría del derecho, cuyo rasgo más distintivo sería la reincorporación de la moral al derecho, a través de los principios de justicia material

${ }^{13}$ Adscripciones específicas de determinados autores a la "corriente neoconstitucionalista", como la que hace Carbonell respecto de Ferrajoli y Zagrebelsky en el estudio introductorio a Zagrebelsky, G., Historia y constitución, Trotta, Madrid, 2005, p. 22, son más bien raras.

${ }^{14}$ Carbonell, M., "El neoconstitucionalismo en su laberinto", en Carbonell, M. (coord.), Teoría del neoconstitucionalismo, Trotta, Madrid, p. 9. 
que se encontrarían presentes en los textos constitucionales, y el consecuente -y militante- rechazo del positivismo jurídico como inadecuado para dar cuenta de esta reincorporación.

\section{Los RAsgos PROPIOS DEL NEOCONSTITUCIONALISMO. CRÍtica}

Como se ha visto arriba, el neoconstitucionalismo correspondería (según sus sostenedores) a una etapa del constitucionalismo -el de la post Segunda Guerra Mundial-que muestra rasgos particulares en su evolución, ya enunciados. A continuación se examinarán con más detalle, y de manera crítica, aquellos que parecen constituir el núcleo de lo que se ha venido en nombrar con el término de marras.

\section{a) Constituciones rígidas, con garantía jurisdiccional y alta "densidad" normativa, o alto contenido normativo}

En contraste con lo que habría sido el modelo anterior a la Segunda Guerra Mundial, se sostiene que las constituciones posteriores ella se caracterizarían por ser constituciones que sustraen el procedimiento de reforma constitucional de manos del legislador ordinario y establecen procedimientos especiales y agravados para la reforma; pero no solamente eso, sino que, adicionalmente, ponen a la mayor parte de la producción normativa bajo tutela de la jurisdicción constitucional. Adicionalmente, se sostiene, las constituciones habrían incrementado su contenido normativo y, más precisamente, los contenidos normativos idóneos para determinar el examen material del ejercicio de las competencias públicas (y, bajo el postulado del efecto horizontal de los derechos fundamentales, también del ejercicio de las libertades individuales).

Ferrajoli relaciona el surgimiento de las constituciones rígidas con la evolución del estado legislativo de derecho al estado constitucional de derecho: Señala este autor que "un segundo cambio, no menos radical, es el producido en este último medio siglo con la subordinación de la legalidad misma -garantizada por una específica jurisdicción de legitimidad-a Constituciones rígidas, jerárquicamente supraordenadas a las leyes como normas de reconocimiento de su validez. (...) La subordinación de la ley a los principios constitucionales equivale a introducir una dimensión sustancial no sólo en las condiciones de validez de las normas, sino también en la naturaleza de la democracia, para la que representa un límite, a la vez que la completa. Un límite porque a los derechos constitucionalmente establecidos corresponden probibiciones y obligaciones impuestas a los poderes de la mayoría, que de otra forma serían absolutos"15.

El problema de este planteamiento de Ferrajoli es que resulta algo impreciso, desde que presenta como novedad diversos elementos que no tienen este carácter. Por lo pronto, la idea de constituciones rígidas, no disponibles para el legislador ordinario, está presente ya en el constitucionalismo decimonónico; del mismo modo, la idea de

${ }^{15}$ Ferrajoli, L., "Pasado y futuro...", cit., pp. 18, 19. 
que estas constituciones, y los derechos que contienen, constituyen un límite sustancial (y no sólo procedimental) para las mayorías legislativas. Aun cuando el procedimiento de control se lleve a cabo en las respectivas instancias políticas, es poco prolijo silenciar esta circunstancia, como si recién tras la Segunda Guerra Mundial los derechos constitucionales viniesen a corresponder a "probibiciones y obligaciones impuestas a los poderes de la mayoría, que de otra forma serían absolutos".

Por toda demostración, baste remitir a la lectura del preámbulo de la Declaración de Derechos del Hombre y del Ciudadano de la Asamblea Nacional, de 26 de agosto de 1789, y, en el ámbito latinoamericano, la evolución del amparo mexicano como forma de control de la constitucionalidad de las leyes y de los actos de las demás autoridades públicas, ya desde la segunda mitad del siglo XIX ${ }^{16}$. La idea de los catálogos de derechos y su función como criterio para evaluar la validez del actuar de todos los poderes públicos no puede ser, por tanto, adscrita a una evolución del vigésimo siglo. Lo que puede aceptarse de la propuesta de Ferrajoli es un concepto de rigidez constitucional (que, dicho sea de paso, es moneda corriente en el tráfico de la teoría constitucional) que une, a la regulación de procedimientos específicos para el ejercicio del poder constituyente derivado, la existencia de una instancia jurisdiccional de control de constitucionalidad que pueda pronunciarse sobre la constitucionalidad específica del acto legislativo (y no solamente sobre el resultado de la aplicación de la ley integrada a un sistema de fuentes presidido por la constitución, en un proceso concreto).

Por su parte, Luis Prieto Sanchís ha sostenido que el neoconstitucionalismo viene a resolver un dilema entre constituciones garantizadas sin contenido normativo, y constituciones con contenido normativo más o menos denso, pero no garantizadas ${ }^{17}$. El neoconstitucionalismo implicaría un modelo de constituciones normativas y garantizadas. Al menos en estos términos, tal afirmación debe ser matizada, ya que no corresponde a la evolución general de las constituciones de postguerra. Las constituciones surgidas con posterioridad a 1945 mantienen, en lo esencial, las características del constitucionalismo decimonónico; una parte orgánica, con el diseño fundamental del órgano parlamentario, la formación del gobierno, la jefatura de Estado y sus relaciones reciprocas; las bases de la judicatura; los principios y competencias del Estado federal, o regional, según corresponda, los procedimientos de su reforma (agravados en comparación con aquellos necesarios para la elaboración de las leyes) y un catálogo de derechos más o menos desarrollado. Sobre esta base, lo novedoso del diseño constitucional de las constituciones italiana y alemana está en la inclusión de un órgano de jurisdicción constitucional, de competencias acotadas, en la primera, y extendidas, en la segunda. De ambas, sólo el Tribunal Federal Constitucional de la Ley Fundamental de Bonn está dotado de la competencia para conocer de quejas por infracción a derechos fundamentales (Verfassungsbeschwerde), y sólo la Constitución italiana

${ }^{16}$ No se hace mención al judicial review norteamericano porque se ha acotado el análisis al ámbito de desarrollo del propio neoconstitucionalismo: Europa y Latinoamérica. Obviamente, su inclusión amplía los argumentos para demostrar que el radical cambio de paradigma tras la Segunda Guerra Mundial, a que hace alusión Ferrajoli, no es tal, o al menos no lo es en mucho de lo que este autor parece sugerir.

${ }^{17}$ Prieto, L., "Voz...", cit., p. 29. 
antepone, al catálogo de derechos (art. 13 a 28), un conjunto de principios fundamentales (arts. 1 a 12) e incorpora un conjunto de enunciados relativos a las relaciones ético-sociales y económicas (arts. 29 a 47), dentro de los cuales se identifican derechos que hoy se adscriben a la categoría de económico-sociales.

En contraste, y tras la fallida experiencia de 1946, la constitución francesa de 1958 contempla un órgano político de control de constitucionalidad de las leyes, el Consejo Constitucional, con un diseño de propósito original bastante claro: evitar la inmisión del legislador en el ámbito de la potestad reglamentaria presidencial (iy no velar por una regular sujeción de las leyes a la constitución!). Esta carta prescinde absolutamente de un catálogo de derechos, así como de enunciados de principios, y se limita a hacer referencia, en su preámbulo, a los derechos consagrados en la Declaración de 1789 y a los de la carta de 1946. Recién las constituciones de Portugal (1976) y España (1978), elaboradas al término de regímenes autoritarios, reúnen en un mismo texto constitucional los rasgos enunciados como propios del neoconstitucionalismo: constituciones con garantía jurisdiccional ${ }^{18}$ y textos de alta densidad normativa ${ }^{19}$.

\section{b) Constituciones con fuerza normativa vinculante, aplicación directa y constitucionalización del derecho}

Dentro de los rasgos que efectivamente destacan en el diseño y praxis institucional posteriores a 1945 está la inclusión de la constitución en el sistema de fuentes para la aplicación operativa del derecho. Dentro de las variadas comprensiones que hay de ella, la idea de fuerza vinculante de la constitución se entiende como opuesta a una noción de constitución como manifiesto político cuya concreción e inclusión en el ordenamiento jurídico queda entregada a las demás fuentes del derecho. Dicho en términos precisos, la fuerza vinculante de la constitución implica que el texto constitucional es considerado, en el mismo plano que las demás fuentes escritas, como base para la construcción normativa, sin que las respectivas partes del texto constitucional puedan ser ocluidas, en su función normativa, por el alegato de necesidad de complemento de la ley o de otro acto creador de textos normativos. De allí que pueda identificarse la noción de fuerza vinculante de la constitución con la de su aplicación directa (sin necesidad de intermediación). El fenómeno de constitucionalización del derecho, en cambio, requiere de unas condiciones copulativas que exceden el mero reconocimiento de la fuerza vinculante de la constitución. Junto a la la existencia de una constitución

${ }^{18}$ En el caso de Portugal, con una doble garantía: la prohibición dirigida a los tribunales de aplicar a los hechos sometidos a su enjuiciamiento normas que infrinjan la Constitución (art. 204), y la existencia de un Tribunal Constitucional (arts. 221 y ss.).

${ }^{19}$ La expresión "densidad normativa” es frecuente en los textos o autores que pueden adscribirse al neoconstitucionalismo, y da cuenta de un enfoque que posteriormente se manifiesta en su forma de entender los procesos de construcción normativa a partir de los textos. Cuando se habla de "densidad normativa" en realidad de lo que se está hablando es de textos constitucionales que incorporan enunciados sobre principios de organización política o social, o bien desarrollan el catálogo de derechos. Más que de densidad normativa, entonces, se trata de desarrollo o extensión textual. 
rígida, mecanismos de garantía jurisdiccional de la constitución, y la asunción de su fuerza vinculante, Guastini menciona otros cuatro requisitos para que se pueda hablar propiamente de constitucionalización del ordenamiento jurídico: la sobreinterpretación de la constitución, la aplicación directa de las normas constitucionales, la interpretación conforme de las leyes y la influencia de la constitución sobre las relaciones políticas. La sobreinterpretación de la constitución presupone su fuerza vinculante y corresponde a un enfoque interpretativo inclinado por la interpretación extensiva de tal manera que resulta posible extraer de ella “...innumerables normas implícitas, no expresas, idóneas para regular cualquier aspecto de la vida social y política" ${ }^{20}$. De ello resulta que toda decisión legislativa está prerregulada y no quedan márgenes para la discrecionalidad legislativa ni para una doctrina de las cuestiones políticas ${ }^{21}$.

Del enfoque de Guastini es importante resaltar su opinión respecto de que tanto la sobreinterpretación de la constitución como la aplicación directa de la constitución corresponden a la postura de los intérpretes, o bien a la actitud de los jueces respecto de la constitución: la clave del neoconstitucionalismo es comprender que no corresponde a un desarrollo necesario a partir de la evolución del constitucionalismo de la postguerra, sino que a ciertas opciones asumidas por ciertos agentes institucionales e intelectuales. La aplicación directa de las normas constitucionales dependería, según Guastini, de la difusión, en el seno de la cultura jurídica, de cierta concepción de la constitución, y de la actitud de los jueces, derivada de la misma, y consistiría en que las normas constitucionales "pueden producir efectos directos y ser aplicadas por cualquier juez con ocasión de cualquier controversia" 22 .

La interpretación conforme de las leyes se aplica en aquellos casos en que, de dos alternativas de interpretación de la ley, una de ella se adecua a la constitución y la otra se presenta como incompatible con ella, y se opta por aquella que es compatible (conforme) con la carta fundamental ${ }^{23}$.

${ }^{20}$ Guastini, R., “La ‘constitucionalización'...”, cit., p. 54.

${ }^{21}$ Guastini se limita a describir las condiciones para la constitucionalización del ordenamiento jurídico, sin que parezca tomar una postura a favor de ella; más bien, en algunos casos, adopta una cierta distancia crítica.

${ }^{22}$ Guastini, R, “La 'constitucionalización'...”, cit., p. 55.

${ }^{23} \mathrm{La}$ interpretación conforme a la constitución admite dos variantes, una de ellas exenta de críticas y la otra altamente cuestionable. La primera variante opera en el nivel de aplicación operativa de la ley; no hay objeciones a involucrar a la constitución como elemento de interpretación de la ley de forma tal de conducir el proceso interpretativo al resultado conforme con la constitución. Un uso diferente de la noción de interpretación conforme a la constitución es aquel que emplea el órgano de jurisdicción constitucional cuando agrega, a la declaración de constitucionalidad de un precepto de ley, o proyecto de ley controlado, su declaración respecto del sentido en que debe ser interpretado: dicho de otro modo, usa el argumento de "la interpretación conforme" para asumir una labor colegislativa (positiva) al generar, junto al de la ley, un texto de función normativa equivalente (la respectiva declaración aditiva de "interpretación conforme”). 


\section{c) Los derechos fundamentales como valores y el enfoque axiológico del neoconstitucionalismo}

El origen inmediato de la evolución que lleva a la consideración de los derechos fundamentales como valores, tanto en la jurisprudencia como en la doctrina, es la sentencia del Tribunal Constitucional Federal alemán en el caso Lüth, mencionada tantas veces que no amerita mayor explicación aquí. En conexión con la teoría constitucional desarrollada por Rudolf Smend en el período de entreguerras, y con la cuestión jurídica a resolver en el caso (una expresión del Código Civil alemán de función jurídica equiparable a la del castellano "buenas costumbres"), la sentencia en este caso califica a la parte de los derechos fundamentales de la Ley Fundamental de Bonn como constitutiva de un "orden objetivo de valores" (eine objektive Wertordnung). Como segundo hito en este camino puede mencionarse el desarrollo doctrinal que se intenta a partir de una lectura de la Ley Fundamental de Bonn y de la jurisprudencia del Tribunal Constitucional Federal alemán, realizada por Robert Alexy en su Teoría de los Derechos Fundamentales. En esta obra, Alexy sostiene que los preceptos sobre derechos fundamentales constituyen principios, y éstos, a su vez, son la expresión, en términos de deber ser, de los valores, ubicados en el plano del ser. Desde un punto de vista normativo, los principios se caracterizarían por ser mandatos de optimización. A partir de la difusión de la obra de Alexy en italiano y en castellano, junto con el prestigio alcanzado por el Tribunal Constitucional Federal alemán y su jurisprudencia, la calificación de los derechos fundamentales como valores o principios se hace patrimonio común del componente teórico del neoconstitucionalismo.

Lo notable de esta faceta del neoconstitucionalismo es que tal calificación -la de los derechos fundamentales como valores- no suele, salvo excepciones, ir acompañada de una discusión o al menos de una toma de posición respecto de qué es lo que se entiende por "valor", como si no se tratase de uno de los términos de sentido más elusivo en las ciencias humanas y sociales. Quizás lo más destacable, en este punto, del neoconstitucionalismo, no sea la afirmación (trivial en un sentido, altamente compleja desde un punto de vista lógico en otro) de que los derechos fundamentales son valores, o constituyen valores (o cualesquiera otras expresiones similares), sino que la ausencia del intento por precisar en qué consiste este predicado, o de justificar un sentido para el mismo ${ }^{24}$ o de hacerse

${ }^{24}$ Baste recordar que una corriente importante de la filosofía del lenguaje (al menos, el empirismo lógico del Círculo de Viena, en especial Rudolf Carnap en Logysche Syntax der Sprache y Philosophy and Logical Syntax) sostiene la ausencia de sentido lógico como predicado de conocimiento de los juicios de valor. Un juicio de valor, como acto de habla, no predicaría algo del objeto del que se habla, sino del sujeto hablante: algo no es bello, o feo, sino en la medida en que quien habla sobre dicho algo lo considera feo o bello. Los juicios de valor expresarían actitudes de los sujetos hablantes. La trampa, en el caso de valores éticos, es que por regla general se puede llegar a ejemplos en que, por la forma en que se reproduce el lenguaje como metainstitución, resulta difícil para el hablante defender la postura de que se trata de una mera actitud subjetiva. Esta cualidad intrínseca del lenguaje, que permite sostener que el gato está encima de la esterilla pero no lo creo, crea fácilmente la ilusión del consenso sobre los valores, o bien permite adscribirlos a la dimensión de categorías independientes de la experiencia, categorías a priori, como hace Scheler. Y es ilusión, porque en el plano ético la cuestión no es tanto despejar la incógnita relativa al valor de una entidad, sino de las 
cargo, incluso en las doctrinas que sostienen la existencia de un orden material de valores, del problema de la compatibilidad entre la percepción de los valores y el orden racional (tómese por ejemplo solamente la teoría de Scheler y su necesidad de introducir la categoría de "sentimientos intencionales" para eliminar un reproche de mero emotivismo subjetivo en la intuición moral). La única obra que se ha considerado en este estudio que aborda directamente el tema, si bien con una nomenclatura que no alude a valores, sino que a la moral, es la de Carlos Santiago Nino, Ética y Derechos Humanos. Sin embargo, su respuesta a la pregunta clave que subyace tanto a un discurso en base a valores como al discurso moral en general, a saber, cómo se pueden justificar los preceptos morales, o simplemente, la moral, consiste en plantearla como una paradoja: “...no se ve qué tipo de justificación se busca cuando se pregunta por la justificación de la moral: una justificación presupone por definición acudir a ciertos principios, y no se advierte a qué principios podemos acudir para justificar principios últimos, o las reglas que permiten derivar tales principios" 25 . Se puede compartir plenamente la segunda oración de esta cita; pero, a partir de ella, resulta altamente criticable el mantenimiento, a un mismo tiempo, de este predicamento y de la tesis que afirma que es posible una justificación racional, basada en la moral, de las decisiones jurídicas. Porque si en definitiva la moral no admite justificación racional, esto significaría que una decisión jurídica basada en juicio morales no puede encontrar, tampoco, una justificación racional.

Por otro lado, la calificación de los derechos fundamentales como valores, y su conversión, en el plano deóntico, a principios, conlleva unas consecuencias que sólo se hacen evidentes al llegar al momento de la aplicación del método de ponderación como vía para la solución de casos concretos en que se presenta colisión de principios (lo que se trata más adelante). Pero es importante destacar un punto: la distinción entre reglas y principios sólo es posible para una teoría que no distingue entre textos normativos y norma como entidad de significado resultante de un proceso de construcción normativa. De este modo, es posible decir de una constitución que en su artículo X expresa "Se garantiza la libertad religiosa", que ella resguarda el principio de la libertad religiosa. Esto no es un predicado respecto de lo que la constitución contiene, normativamente, sino que respecto de cómo se va a leer la constitución: una alternativa sería tratar de desarrollar un proceso interpretativo destinado a justificar ciertas reglas en la fórmula "Se garantiza la libertad religiosa"26.

posiciones relativas de las distintas entidades a las que asignamos la cualidad de valor. Tomando en cuenta que es justamente éste el plano en el cual se mueve la argumentación jurídica en base a valores, lo mínimo que podría pedirse a cualquiera afirmación de los derechos fundamentales como valores sería una definición básica del concepto de valor que maneja, y su toma de posición respecto del problema epistemológico que plantean los juicios de valor.

${ }^{25}$ Nino, C., Ética y derechos humanos, Astrea, Buenos Aires, 1989, p. 126.

${ }^{26}$ Intento no sólo posible, sino de un alto rendimiento. A partir de un análisis de la función política que cumple esta garantía en la evolución de los conflictos religiosos de los siglos XVII a XIX es posible justificar una serie de reglas muy precisas como resultado de la interpretación del precepto sobre libertad religiosa: derecho a celebrar el culto privado y el público, a erigir templos, a no ser discriminado en la función pública por razones religiosas, a enseñar la propia religión y realizar proselitismo religioso, la autonomía organizativa de las entidades religiosas respecto del Estado, etc. Como se puede apreciar, es la opción del intérprete respecto de qué es lo que va a "buscar" en el respectivo precepto la que anticipa qué es lo que podrá encontrar en él. 
Un segundo punto teórico a resaltar es la distinción entre reglas y principios como parte de la argumentación jurídica. La argumentación jurídica siempre va dirigida a producir una regla y sólo una regla aplicable al caso. No es posible la construcción racional de un sistema argumental que permita sostener que en un caso se puede predicar que "debe ser A", y que, en el mismo caso, sin variación en los elementos jurídicamente relevantes, "debe ser B". El método o enfoque principialista confunde no sólo las entidades semióticas (las señales) con las entidades semánticas (de significado), sino que también el proceso de construcción normativa (que incluye la consideración, examen, afirmación, descarte, recuperación, etc. de reglas y principios) con el resultado de la construcción normativa que siempre ha de ser un juicio que permita calificar un deber ser disyuntivo ("debe ser" o "no debe ser": y no, en cambio, "debe ser en mayor o menor medida"). Se profundizará en este tema al tratar el método de ponderación.

La afirmación de que los derechos fundamentales constituyen valores, o un orden de valores, así como la más amplia afirmación de que ciertos principios constitucionales se insertan dentro de un sistema axiológico, (re)introduce un reflexión iusteorética sobre la relación entre el derecho y la moral que se identifica como un rasgo propio del neoconstitucionalismo. La afirmación básica de este postulado podría sintetizarse, tomando como fuente el fallo Lüth y el trabajo de R. Dworkin, en la siguiente afirmación: el derecho está formado por principios fundamentales que tienen su fuente en una moral objetiva expresada en la constitución. Los principios de justicia, de índole moral, se encontrarían desde sus orígenes positivados en los textos constitucionales, como meras declaraciones políticas sin incidencia práctica ${ }^{27}$. Lo que habría cambiado ahora-digamos, en tiempos del neoconstitucionalismo- sería que estos principios, con el advenimiento de la constitución como norma con fuerza vinculante y directamente aplicable, se habrían juridificado, produciendo de esta manera la conexión entre moral y derecho y los requerimientos de un nuevo enfoque, o método, para enfrentar estos principios morales en la aplicación del derecho (en especial del derecho constitucional al resto del ordenamiento jurídico). De este modo, la vigencia de las fuentes del derecho, vista desde el punto de vista de su producción conforme a los procedimientos previstos en el ordenamiento jurídico y dentro de éste, del orden constitucional, queda ahora supeditada o al menos indisolublemente unida a la cuestión de la validez de dichas fuentes a la luz de los principios (morales) contenidos en la fuente superior que, por su primacía, condiciona en esta dimensión de validez también la dimensión de vigencia de las demás fuentes.

Este postulado plantea problemas teóricos y metodológicos de envergadura. Por lo pronto, y aunque se autoentiende como un rechazo o superación del positivismo (en este plano, junto a la voz neoconstitucionalismo es usual encontrar la referencia a este enfoque como postpositivismo) no se aporta una explicación de por qué la constitución, que en sí es derecho puesto, en el respectivo acto constituyente tendría la especial aptitud, en cuanto tal derecho puesto, para recibir y positivar una moral objetiva, y no así el resto de las fuentes

${ }^{27}$ Pozzolo, S., "Un constitucionalismo ambiguo", en Carbonell, M. (coord.), Neoconstitucionalismo(s), Trotta, Madrid, 2003, p. 191. 
del ordenamiento jurídico. La única forma de entender este fenómeno sería atribuir al poder constituyente originario una cualidad distinta a la de otros poderes normativos: no sólo en el plano que permite explicar la legitimidad de un orden fundamental que no se remonta, a su vez, a una norma jurídica, sino también en un plano que permita explicar cómo, o a título de qué, se transforma en legislador moral de la respectiva comunidad política. Esto plantea una suerte de paradoja metafísica ya que implica afirmar que los actos del poder constituyente, siendo, tal como las leyes y demás actos de creación de textos normativos obra de seres humanos, o sea, fuentes de derecho positivo, tendrían, sin embargo, una naturaleza distinta que la de éstos. Lo notable de esta paradoja es que, para el lector avisado, no podrá pasar desapercibida lo cerca que ella deja a las tesis neoconstitucionalistas de los planteamientos teóricos de Kelsen, con una variante; para Kelsen, en el plano lógico, la norma constitucional ha de fundarse en una norma hipótetica, supuesta para dar coherencia al sistema jurídico. La afirmación de la constitución como receptora de principios morales o valores como entidades, y en este carácter cualitativamente distinta del resto del ordenamiento jurídico -a pesar de que "por hombres fuiste creada y no por dioses"-, parece absorber en sí misma su propio fundamento (la constitución es un valor, ha dicho M. Dogliani) y ser, en este sentido, más positiva ${ }^{28}$ que la propia idea de constitución de Kelsen. Si, por el contrario, este postulado teórico quiere abandonar su carácter paradojal, debe aceptar que, como obra humana que es, la constitución no es distinta a otras fuentes del derecho y, si lo que ha de primar es un imperativo moral, incluso la constitución habría de quedar sometida a él para afirmar su validez. El postulado teórico se desprende así de su antifaz y muestra, honestamente, su verdadero contenido.

Sin embargo, estos problemas, que, ni con mucho, son abordados al momento de plantear la conexión reseñada entre derecho y moral, son menores frente a los que plantea la aplicación práctica de una tesis de conexión entre derecho y moral como la que se despliega en algunas tesis vinculadas al neoconstitucionalismo.

La racionalidad de un sistema jurídico está en directa relación con la función comunicativa que cumple el respectivo sistema semiótico para conectar las consecuencias de determinados actos al sentido que es posible anticipar para los mismos. Dicho de otro modo, un sistema jurídico es tanto más racional cuanto más es posible constatar una regularidad entre las predicciones que permite su sistema de fuentes sobre las consecuencias de determinados actos, y las consecuencias que se atribuyen a los mismos, al menos en la instancia jurisdiccional. A la inversa, la racionalidad del sistema decae si, frente a un conjunto de fuentes, no es posible o resulta muy difícil predecir cuál podría ser la decisión para el caso. Desde esta perspectiva, Comanducci aborda una primera dificultad que plantea la comprensión de un sistema jurídico derivado de una cantidad de principios fundamentales fundados en la moral objetiva, en lo que él llama la determinación ex ante del derecho. Comanducci sostiene que, dado que la configuración de los principios no puede eliminar la parcial indeterminación del derecho, eventualmente podría reducirlas si se dieran al menos dos condiciones;

${ }^{28}$ Ya que encuentra su fundamento en sí misma, sin ni siquiera requerir el artefacto teórico kelseninao de la norma hipotética. 
la existencia de una moral objetiva, conocida y observada por los jueces, y la construcción de un sistema integrado de derecho y de moral internamente consistente ${ }^{29}$. Pero en el plano de los hechos, este autor constata cuatro obstáculos que, incluso dejando de lado la cuestión de fondo (si es posible afirmar la existencia de una moral objetiva), no permiten el cumplimiento de estas condiciones: suponiendo que existiese una moral objetiva, no todos los jueces las conocen ni/o comparten; al menos a nivel de los jueces, no existe una moral positiva compartida por todos ellos; los jueces no son coherentes en el tiempo con sus propias decisiones, ni se ocupan de elaborar un sistema consistente de derecho y moral para resolver los casos y, por último, los jueces no siempre deciden ni argumentan racionalmente. Por el contrario, Comanducci constata que la configuración de principios no sólo no ayuda a disminuir, sino que tiende a aumentar la indeterminación ex ante del derecho, por la vaguedad de los principios frente a las reglas (ya que impide conocer por anticipado cuál es la conducta que será considerada conforme a los principios, E.A.L.); porque a falta de una moral común ${ }^{30}$, la creación y configuración de principios aumenta la discrecionalidad de los jueces para decidir los casos fundados en su particular concepción de justicia (y esta apertura a las posibilidades de decisión a su vez aumenta la indeterminación ex ante) y por último porque este campo de discrecionalidad, de por sí ampliado al configurar las posibilidades de decisión sobre principios, se expande aún más en su aplicación caso por caso y sin marco alguno de jerarquía entre principios, como se da a través de la ponderación ${ }^{31}$.

Un segundo problema que plantea la tesis de conexión entre derecho y moral, entendida en el sentido de que “...cualquier decisión jurídica, y en particular la decisión judicial, está justificada si deriva, en última instancia, de una norma moral"32, está emparentado con la ya comentada ausencia de reflexión sobre los valores, al momento de calificar los derechos fundamentales como valores. Porque si se asume esta tesis ¿qué tipo de norma moral debiese ser aquella que justifica la decisión judicial? ¿La moral individual del juzgador, con independencia de si se conforma o no a la moral positiva? ¿Aquella que resulta de un discurso racional, como moral crítica? ${ }^{33}$ Podría decirse que estas son precisamente las cuestiones que resuelve la remisión a una moral objetiva plasmada en la constitución. Sin embargo, esto no

\footnotetext{
${ }^{29}$ Comanducci, P., "Formas de (Neo)Constitucionalismo...", cit., p. 92.

${ }^{30} \mathrm{O}$ mejor, de una moral garantizada como común, E.A.L.

${ }^{31}$ Comanducci, P., "Formas de (Neo)Constitucionalismo...", cit., p. 92-93.

32 Comanducci, P., "Formas de (Neo)Constitucionalismo...", cit., p. 94.

33 Comanducci plantea como alternativas para responder a la pregunta de cuál sería la norma moral
} justificativa de la decisión judicial: a) una norma moral objetiva verdadera (correspondiente a "hechos morales"); b) una norma moral objetiva racional (aceptable por un auditorio racional); c) una norma moral subjetivamente escogida; d) una norma moral intersubjetivamente aceptada. Las dos primeras serían reconducibles a la tercera y ésta implicaría dejar del todo la decisión en manos del juez, tornándose el derecho o bien en inútil (cuando confirma la norma moral elegida por el juzgador) o prohibido (porque contraría a la norma moral). Comanducci señala: "La certeza del derecho quedaría confiada solamente a la conciencia moral de cada juez" (Comanducci. P., "Formas de (Neo)Constitucionalismo...", cit., p. 95): más exacto sería decir que el derecho mismo quedaría confiado, en este esquema, a la conciencia moral de cada juez. La cuarta alternativa obligaría al juez a transformarse en un sociólogo para determinar cuál es la moral positiva vigente en una sociedad en un momento determinado, lo que, dado el pluralismo ético imperante en las sociedades contemporáneas, lo obligaría a optar por una de ellas, volviendo de este modo a la tercera opción. 
es así: el texto constitucional no se torna ni más claro ni más evidente porque sustituyamos el respectivo derecho fundamental, o principio, por el correspondiente valor. El discreto rendimiento que el texto constitucional presenta para la construcción normativo-jurídica del derecho a la vida no cambia cuando se busca comprender el contenido (moral) del valor vida o del valor que es el derecho fundamental a la vida. De este modo resulta evidente que la comprensión de los derechos como valores, o de cualesquiera otros valores en su faz de principios, y su inclusión dentro de la argumentación jurídica (o jurídico-moral) está condicionada por el orden o sistema moral al cual se adscriba el decisor.

\section{d) El método de la ponderación y la superación del positivismo}

En directa relación con el postulado de la relación entre moral y derecho a través de los derechos fundamentales como valores y, en general, de los principios fundamentales como principios de justicia material fundados en la moral, se encuentra uno de los postulados que destacan dentro del neoconstitucionalismo, en lo que se ha venido en llamar su dimensión metodológica, y que consiste en la defensa del método de ponderación. La ponderación sería el método adecuado para el manejo de categorías morales que, por una parte, no se dejan aplicar como las reglas por la vía de la subsunción y que, por otra, sostienen una pretensión de validez que no se ve desplazada por las reglas tradicionales empleadas para la solución de antinomias o colisiones normativas. En el caso de colisión de principios (en particular de los principios constitucionales) ninguno de aquellos en conflicto se vería atenuado o neutralizado en su pretensión de validez; se trataría simplemente de determinar, para el caso concreto, el grado de preponderancia, o de mayor peso relativo, que se otorga a uno frente a otro, sin que ello implique un menoscabo en el estatus normativo de cada uno de ellos. La idea subyacente es que, mientras a nivel normativo los principios conservan siempre la misma e invariable validez, las circunstancias del caso concreto pueden introducir elementos de juicio que permitan dar, en ese caso, mayor peso a uno que a otro ${ }^{34}$. Queda de este modo abierta la posibilidad de, en otro caso, dar prevalencia al principio que en un caso anterior ha sido preterido.

El método ponderativo, como se puede entender por una de sus acepciones en el diccionario, así como por la explicación que del mismo da uno de sus principales adalides, Robert Alexy, es un método que llama al intérprete operativo (tanto de la constitución como de las leyes, en un contexto de constitucionalización del derecho) a sopesar, esto es, a apreciar comparativamente el peso de los respectivos principios concurrentes en un caso concreto $^{35}$. Del otorgamiento de un mayor o menor peso relativo a estos principios

${ }^{34}$ Dworkin, R., Los derechos en serio, Ariel, séptima impresión (de la primera impresión de 1984), 2009, p. 77: "Los principios tienen una dimensión que falta en las normas: la dimensión del peso o importancia. Cuando los principios se interfieren...quien debe resolver el conflicto tiene que tener en cuenta el peso relativo de cada uno".

35 Alexy describe el núcleo de la ponderación como el juicio relativo a una relación condicionada de precedencia. Alexy, R., Teoría de los derechos fundamentales, Centro de Estudios Constitucionales, Madrid, 1993 , p. 157. 
-igualmente válidos y "pesados" si se les considera en abstracto- resulta la justificación de la decisión en el proceso de ponderación. A su vez, el curso de la ponderación, desde un punto de vista argumental, adopta cabalmente la estructura del control de proporcionalidad desarrollado originalmente como estándar de control del ejercicio de potestades discrecionales de la autoridad administrativa (que Alexy aplica precisamente con esa denominación, al espacio de discrecionalidad del legislador ${ }^{36}$ ).

El análisis de la proporcionalidad de una medida concreta, o de actos de naturaleza normativa, conduce a un juicio de proporcionalidad o falta de proporcionalidad por la vía de tres pasos; el examen de la idoneidad de la medida o acto para alcanzar fines legítimos, el examen de la necesidad de la afectación de un derecho (o, habría que generalizar, de un principio fundamental), frente a la posibilidad de lograr el fin pretendido con un menor gravamen para el derecho o principio de que se trate ${ }^{37}$, y el estudio de la proporcionalidad en sentido estricto, entendida como el grado de afectación del respectivo derecho o principio en vistas a la entidad del fin perseguido y el grado en que se puede alcanzar el mismo, a partir de dicha afectación. La relación que debe establecerse la expresa Alexy en los siguientes términos: "Cuanto mayor es el grado de la no satisfacción o de afectación de uno de los principios, tanto mayor debe ser la importancia de la satisfacción del otro" 38 . Como lo indica su estructura, este juicio conlleva a su vez tres elementos: una determinación del grado de no satisfacción o afectación de uno de los principios, la determinación del grado de satisfacción del otro principio, y la consideración de si ambas entidades, puestas en relación, justifican o no justifican la medida (o sea, la no satisfacción o afectación asumida para uno de los principios).

El método de la ponderación puede apreciarse, en un sentido crítico, desde dos perspectivas.

La primera de ellas es estructural; desde el punto de vista de la estructura lógica que propone, el método de ponderación deja al operador jurídico justo allí donde se plantea el problema: cómo justificar normativamente la preferencia por uno u otro principio, el mayor peso relativo que se otorga a uno u otro valor en un caso concreto. Si los valores que se sostienen presentes en el documento constitucional cumplen su función normativa al ser involucrados como tales en el juicio de ponderación, las razones en virtud de las cuales opera la preferencia condicionada en la que consiste el juicio de ponderación son independientes de tales valores y, por tanto, se encuentran del todo desvinculadas de la fuente jurídica de la decisión. Las valoraciones adicionales requeridas por la operación, a saber, la decisión del peso a adjudicar a cada uno de los valores en juego, quedan entregadas al operador sin punto de apoyo o referencia jurídica (y habría que agregar: ni siquiera argumental).

36 Alexy, R., "Epílogo a la Teoría de los Derechos Fundamentales", en Revista Española de Derecho Constitucional, año 22, número 66, septiembre-diciembre, 2002, p. 21.

${ }^{37} \mathrm{O}$, expresado de manera muy clara, el principio de necesidad equivaldría a una prohibición de sacrificios innecesarios para los derechos fundamentales. Alexy, R., "Epílogo a la Teoría...", cit., p. 29.

${ }^{38}$ Alexy, R., Teoría de los derechos..., cit., p. 161. 
La demostración de este aserto respecto de cada uno de los elementos del juicio de ponderación la aporta Juan Antonio García Amado en un artículo ${ }^{39}$ en que, respecto de cada uno de ellos, realiza el análisis de los ejemplos paradigmáticos utilizados por el propio Alexy para mostrar la operatividad del juicio de ponderación, y expone el punto de la argumentación en que ingresa una decisión no justificada (más bien, ocluida) que permite producir una justificación aparente vía ponderación. Así, lo relevante en el juicio de idoneidad no es el juicio de adecuación fáctica de la medida al fin perseguido, sino la elección de determinado fin, como perseguido, para realizar dicho juicio, cuestión que queda absolutamente a discreción del intérprete.

En el caso del análisis de la necesidad, el quid de la cuestión estaría radicado, por un lado, en los valores o principios que se escogen para enfrentar las correspondientes alternativas que son incluidas o, más relevante aún, excluidas del análisis comparativo para llegar a demostrar que la afectación emprendida es necesaria ${ }^{40}$. Ambas elecciones (decidir confrontar la libertad de expresión con el derecho a la salud y no con la libertad empresarial, por ejemplo; o bien afirmar que no se observan otras posibilidades para lograr el fin perseguido, evitando considerar alternativas racionales, como por ejemplo prohibir la publicidad del tabaco para disminuir las enfermedades asociadas al consumo, antes que imponer la carga de avisar su efecto dañino en la salud) quedan entregadas a la plena libertad del intérprete y exentas de deber de justificación alguna. Respecto del juicio de proporcionalidad en sentido estricto, García Amado demuestra paso a paso cómo el supuesto método ponderativo puede ser aplicado, sin complejidad ninguna, como una clásica operación interpretativa de atribución de significado a términos en zona de penumbra de significado.

La segunda perspectiva dice relación con la afirmación, proveniente de las propias filas del neoconstitucionalismo, de que el método de la ponderación permite superar al método de la subsunción propio del positivismo. Para quien tiene noticia de los debates sobre interpretación jurídica habidos durante el siglo $\mathrm{XX}^{41}$ (y ya anticipados, en muchos

39 García, J. A., "El juicio de ponderación y sus partes. Una crítica” en Alexy R. (coord.), Derechos sociales y ponderación, Fundación Coloquio Europeo, Madrid, 2007.

${ }^{40}$ En este caso, el análisis de García Amado está lleno de humor. Frente al análisis de la carga legal impuesta a las cajetillas de cigarrillos, de llevar un anuncio sobre su dañino efecto para la salud, García Amado se pregunta por qué en el caso de los automóviles no se impone una carga similar indicativa de los riesgos que conlleva manejar, y por qué la alternativa de campañas educativas no sería en el caso de los cigarrillos al menos tan eficaz como lo han sido para reducir los accidentes de tránsito.

41 No es este el lugar para desarrollar este tema pero, a fin de descartar una referencia general sin utilidad alguna, estos debates pueden ordenarse dentro de los siguientes grupos: a) teorías clásicas de la interpretación, entendiendo por tales cualquier teoría que sostiene que los signos lingüísticos están dotados de un significado que les es propio, y que la actividad interpretativa es una actividad cognoscitiva (desde Savigny hasta Engisch y Coing, este último con expresas referencias a Betti); b) la nueva hermenéutica de fines de la década de los 60 (Gadamer, Esser, Larenz); c) la recepción de la escuela analítica del lenguaje con influencias tanto de Wittgenstein como de la lógica semántica bajo el alero de Carnap, y en la cual podría incluirse a Hart; d) una serie de enfoques menos conocidos, como el de la teoría de la comunicación (Horn) y la lingüística pragmática. Una exposición bastante completa puede consultarse en Busse, D., Juristische Semantik: Grundfragen der juristischen Interpretationstheorie in sprachwissenschaftlicher Sicht (Semántica jurídica: 
casos, en la segunda mitad del siglo XIX), esta afirmación del neoconstitucionalismo evoca la imagen de un pasajero de tren que, habiendo abordado el carro equivocado, tras ser desenganchado del tándem original, ve cómo el convoy se aleja, sin él, hacia su destino. Y esto porque, si lo que quiere enfrentar el método de ponderación es al método subsuntivo, debe estar consciente de que, dentro de aquellas posteriores a la Segunda Guerra Mundial casi no hay teoría de interpretación o aplicación del derecho que sostenga que el método de aplicación del derecho es de carácter subsuntivo ${ }^{42} \mathrm{o}$, al menos, que se agota en el momento de la subsunción.

El neoconstitucionalismo pelea así con animales extintos o, mejor dicho, desarrolla una enérgica estrategia para vencer a un fósil. Para desplegar un rendimiento teórico, o una ventaja comparativa respecto de otros, el método ponderativo no debiese mostrarse como alternativa al método subsuntivo -que ya no es una alternativa-, sino que respecto de alguno de los otros métodos discutidos en los últimos 50 o ya casi 60 años.

Si es que cabe hacer algún reproche a una postura teórica o doctrinaria, en general, y este es el caso respecto de la ponderación, es el tener por efecto el bloquear la discusión científica sobre los correspondientes tópicos. Al presentarse como la vía de redención frente a una subsunción incapaz de dar cuenta de las necesidades de la interpretación y aplicación de principios constitucionales, el método de la ponderación reduce todo el campo de debate a una sencilla línea entre dos puntos que, planteados como únicas alternativas extremas -subsumir o no subsumir-, se tornan banales.

La idea de una aplicación subsuntiva del derecho es equivocada por reductiva, ya que refiere a una sola operación lo que son una serie de pasos complejos. En un sentido propio la subsunción está siempre presente en toda operación lógica de aplicación del derecho en cuanto une el plano general y abstracto de la norma con el juicio de su aplicación a un caso concreto. Incluso en la aplicación de un "método" ponderativo. No existe forma, ni siquiera para el método ponderativo, de expresar un juicio final sobre una determinada hipótesis de aplicación del derecho, que no sea subsuntiva en el último eslabón de las operaciones lógicas. $\mathrm{Si}$, tras todos los pasos que se quieran seguir en un ejercicio de derrotabilidad de las reglas generales, excepciones y ponderación de principios $^{43}$ se llega a la conclusión de que, dadas

preguntas básicas de la teoría de la interpretación jurídica desde la perspectiva de la ciencia del lenguaje), Duncker \& Humblot, Berlin, 1993.

42 "Casi"; algunos intentos en la década de los años 70 intentaron enfrentar el problema de la aplicación del derecho y, en particular, el de la interpretación de la ley, como un problema de ambigüedad y polisemia propio del lenguaje natural. Como antídoto se propuso lo que se llamó el "enfoque cibernético", destinado a eliminar los "ruidos" en el sistema jurídico por vía del desarrollo de un lenguaje técnico altamente específico que debía ser rigurosamente empleado por los legisladores y estrictamente seguido por los jueces. El intento no tuvo éxito.

${ }^{43}$ Por ejemplo, la regla impuesta por la ley de que determinado tipo de funcionarios públicos encargados de la seguridad de las personas no deben abandonar su puesto de trabajo; el caso en que suena la alarma de incendio, y el principio de respeto y protección a la vida humana, que puede llevar al juicio de que, si bien frente a una alarma de incendio la regla de que no se debe abandonar determinado edificio se ve "derrotada" ello no libera a los respectivos funcionarios públicos de tomar medidas de seguridad, mientras abandonan el edificio, para proteger la vida de otras personas. El juicio normativo, sin embargo, sólo puede realizarse a la luz de las circunstancias concretas en las cuales se dio o no dio la protección a las personas, y tendrá la 
las condiciones a, b y c entonces se encuentra jurídicamente justificada la decisión $\mathrm{D}$, es porque la decisión D se adopta en un caso concreto que se estima (en realidad, se decide) que corresponde a las condiciones a, b y c.

La subsunción es la operación lógica que permite unir el juicio hipotético y abstracto, a nivel normativo, con la decisión del caso real y concreto, a nivel práctico. Una cosa distinta, y que nada tiene que ver con el proceso de subsunción, es el método aplicado para la construcción normativa, esto es, para llegar a afirmar la vigencia de la norma que luego se aplicará subsuntivamente ${ }^{44}$. En El juicio de ponderación y sus partes ${ }^{45}$, Juan Antonio García Amado demuestra la esencial intercambiabilidad del método subsuntivo y el método ponderativo, proponiendo incluso la solución de un mismo caso a la luz del método subsuntivo y el método ponderativo. Sin compartir la nomenclatura (lo que García Amado llama el método subsuntivo/interpretativo es lo que aquí he tratado como el problema de la construcción normativa) su trabajo aporta una acuciosa demostración de la estructura subyacente a un razonamiento ponderativo y su sustancial equivalencia con el que se ha venido de denominar el método subsuntivo, con la diferencia de que este último "es más apto para que los tribunales cumplan con los requisitos de una argumentación exigente, pues en él se ven más claros los pasos en que la racionalidad exige argumentación expresa de las decisiones determinantes del resultado final" 46.

Es aquí donde engarza una teoría de la argumentación jurídica, en general, y de una argumentación interpretativa cuando la norma ha de construirse sobre la base de textos preexistentes. La única teoría de la interpretación que agota el proceso de aplicación del derecho en la operación de subsunción es aquella que sostiene la presencia de un significado (único y correcto) en las fórmulas textuales utilizadas para la comunicación del derecho, y el carácter aproblemático o evidente de la calificación jurídica de la realidad. Ninguna de ambas

estructura siguiente: dadas las circunstancias a, b y c, debe ser D (por ejemplo, se justificaba que un funcionario público abandonara el edificio y a una persona atrapada en una habitación bloqueada para cuyo socorro no contaba con los medios que permitiesen avizorar al menos una posibilidad de éxito del rescate).

${ }^{44}$ Resulta curioso que, al plantear su modelo de normas y principios y justificar la diferencia entre ambos, Dworkin no repare en que uno de sus ejemplos deja en claro que el trabajo con y sobre la base de principios opera en un mismo proceso de construcción normativa, en su caso, argumental interpretativo. Señala este autor, respecto a la prohibición de la Sherman Act de restricciones irrazonables al comercio: "Esto permitió que la disposición funcionara lógicamente como una norma (toda vez que un tribunal encuentra que la restricción es «irrazonable» está obligado a declarar que el contrato no es válido) y sustancialmente como principio (un tribunal debe tener en cuenta multitud de principios y directrices para determinar si una restricción en particular, en determinadas circunstancias económicas, es «irrazonable»), Dworkin, R., Los derechos..., cit., p. 79. Bien puede reformularse esta idea de Dworkin del siguiente modo: para determinar si una restricción en particular es irrazonable en determinadas circunstancias económicas el tribunal debe tener en cuenta una multitud de principios y directrices, y si a partir de ellas encuentra que la restricción es irrazonable está obligado a declarar que el contrato no es válido. De este modo queda claro que los principios se incorporan en el proceso de construcción normativa de la norma que sustenta la decisión, pero que ésta (la decisión) se toma a la luz de la norma en una opción binaria: la restricción particular o es, o no es, irrazonable.

${ }^{45}$ García, J. A., "El juicio de ponderación...”, cit., pp. 317 y ss. El caso al que se alude en este párrafo es conocido como la publicidad del Toro de Osborne .

${ }^{46}$ García, J. A., “El juicio de ponderación...”, cit., p. 317. 
premisas son aceptadas por las teorías contemporáneas de la interpretación que, incluso en sus variantes más conservadores, reconocen al menos en los casos así llamados de ambigüedad o polisemia un ámbito de decisión para el juzgador como operador semántico.

\section{Conclusiones}

Tras una primera aproximación al neoconstitucionalismo, se concluye que este término puede usarse para aludir a tres sentidos claramente diferenciables. En primer lugar, con la expresión neoconstitucionalismo se puede aludir a determinados rasgos de la evolución constitucional (praxis jurisprudencial, diseño constitucional) de algunos países europeos y latinoamericanos tras la Segunda Guerra Mundial. No puede utilizarse, sin más, para aludir a una etapa del constitucionalismo occidental posterior a la Segunda Guerra Mundial, ya que conlleva necesariamente, dentro de los rasgos que muestran los regímenes constitucionales de post segunda guerra, una selección: la de aquellas características que se han mencionado en el cuerpo de este trabajo.

Por otro lado, estas características no se presentan necesariamente en todos los regímenes constitucionales de Occidente y, en aquellos en que se presentan, lo hacen en disímiles combinaciones. Propondría para este sentido de la expresión el adjetivo de bistórico, para aludir a su uso como referencia a una parte del concreto desenvolvimiento al interior de ciertos regímenes constitucionales contemporáneos. Esta parte comprende el reconocimiento, en la praxis institucional, y ocasionalmente en el propio texto constitucional, de fuerza normativa directa del texto constitucional y su proyección en el sistema de fuentes subconstitucionales (constitucionalización del derecho); creación de competencias jurisdiccionales facultadas para enervar la producción legislativa (ya sea por anulación derivada de inconstitucionalidad, ya sea por inaplicación); praxis jurisprudencial y doctrinaria en torno a un discurso de derechos fundamentales como valores o principios, con eficacia en las relaciones entre particulares, afirmación de la posibilidad de colisión de derechos o principios fundamentales, y aplicación y defensa del método de ponderación para resolverla.

Este neoconstitucionalismo histórico debe diferenciarse, en todo caso, del pluralismo constitucional como fenómeno específico derivado de procesos avanzados de integración, cuyo único ejemplo actual lo presenta la Unión Europea, pero cuya expansión en el futuro debe considerarse como un problema que queda abierto para la teoría constitucional.

En segundo lugar, puede hablarse del neoconstitucionalismo como una corriente dentro del pensamiento jurídico que incluye a una serie de autores cuyo denominador común es la favorable valoración de aquellos rasgos que se agrupan bajo el neoconstitucionalismo histórico. El rasgo sobresaliente de este enfoque no es tanto (o tan sólo) la buena evaluación que hacen del mismo, sino que el descuido o abandono de la reflexión sobre la función de la constitución como constitución política de un Estado, y sus límites. Tomando la propuesta de Comanducci, estimo que al uso del término neoconstitucionalismo para aludir a esta actitud o corriente de pensamiento conviene el adjetivo de ideológico. 
La vinculación del neoconstitucionalismo con el tercer campo de significado que se le puede atribuir presenta alguna dificultad. No parece posible hablar de un neoconstitucionalismo teórico, o de una teoría del neoconstitucionalismo, si por teoría se entiende una construcción que intenta organizar de manera sistemática y completa un cuerpo de conocimientos, dando al mismo coherencia interna. Los postulados que se mencionan como candidatos posibles de una "teoría del neoconstitucionalismo" ni son completos, ni siempre coherentes entre sí. No son completos desde el momento en que, como se ha visto, aspectos importantes de los postulados neoconstitucionalistas reposan en la mera afirmación, sin sustrato adicional, de un aspecto fundamental de los correspondientes ámbitos teóricos. La distinción entre reglas (o normas) y principios omite el análisis, esencial para evaluar su coherencia, de la relación entre "texto" y "sentido", desde el momento en que alude a textos constitucionales contemporáneos "plagados de principios”. Lo curioso es que esta identificación sólo resulta posible desde premisas interpretativas cercanas a la corriente exegética, para la cual el sentido de un texto normativo ya puede desprenderse de su texto (en el caso del tenor literal claro). La falta de complitud permite explicar, también, las incoherencias. Dentro de ellas destaca como una de las más evidentes la que en este trabajo se ha denominado la paradoja metafísica de la constitución: el intento de superar el positivismo a través del recurso a valores o principios morales afincados en la constitución no explica cómo la constitución escrita, en cuanto derecho puesto, tendría una naturaleza distinta a la de las demás fuentes del ordenamiento jurídico.

En definitiva, lo que está en juego en los postulados del neoconstitucionalismo doctrinario -como se propone aquí denominar al conjunto de propuestas que se realizan en el plano teórico, sin llegar a configurar una teoría del neoconstitucionalismo- es el concepto de constitución. Ya sea expresamente -como en el caso de Zagrebelsky-, ya sea porque ello está implícito en sus postulados o en sus consecuencias, el concepto de constitución que maneja el neoconstitucionalismo doctrinario es el de un programa, no sólo político sino también social (en la medida en que no sólo toca el ejercicio y relaciones del poder, sino que también los diversos ámbitos de las relaciones sociales), entregado en su concreción final a la judicatura (y no a la decisión resultante de la movilización política electoral que pueda resultar en el juego de las mayorías) en un contexto argumentativo de un alto grado de subjetividad (por la imposibilidad de disciplinar las opciones de entrada incorporadas en la respectiva ponderación).

En definitiva, las construcciones teóricas se pueden evaluar por sus consecuencias prácticas. En este test, lo que se puede reprochar al neoconstitucionalismo doctrinario es que traslada la discusión democrática de todas las cuestiones políticas verdaderamente relevantes al plano de la formulación del texto constitucional (ya que bajo la constitución todo está ya decidido en germen, y entregado a la ponderación del juez). Se constitucionaliza el derecho, claro está, pero en ese proceso el carácter político fundamental de la constitución se pierde. Dicho de otro modo, puede que lo que compra el neoconstitucionalismo sea bueno; pero el precio que paga es la desconstitucionalización de la constitución. 


\section{BIBLIOGRAFÍA}

Alexy, Robert, Teoría de los derechos fundamentales, Centro de Estudios Constitucionales, Madrid, 1993.

Alexy, Robert, "Epílogo a la Teoría de los Derechos Fundamentales”, en Revista Española de Derecho Constitucional, año 22, número 66, septiembre-diciembre, 2002.

Busse, Dietrich, Juristische Semantik: Grundfragen der juristischen Interpretationstheorie in sprachwissenschaftlicher Sicht (Semántica jurídica: preguntas básicas de la teoría de la interpretación jurídica desde la perspectiva de la ciencia del lenguaje), Duncker \& Humblot, Berlin, 1993.

Carbonell, Miguel, "Nuevos tiempos para el constitucionalismo”, en Carbonell, M. (coord.), Neoconstitucionalismo(s), Trotta, Madrid, 2003, pp. 9-11.

Carbonell, Miguel, "El neoconstitucionalismo en su laberinto", en Carbonell, M. (coord.), Teoría del Neoconstitucionalismo, Trotta, Madrid.

Comanducci, PaOlo, "Formas de (Neo)Constitucionalismo: un análisis metateórico", en Carbonell, M. (coord.), Neoconstitucionalismo(s), Trotta, Madrid.

Dworkin, Ronald, Los derechos en serio, Ariel, $7^{\text {a }}$ impresión de la primera impresión de 1984 , 2009.

Ferrajoli, Luigi, "Pasado y futuro del Estado de derecho", en Carbonell, M. (coord.), Neoconstitucionalismo(s), Trotta, Madrid, 2003.

García Amado, Juan Antonio, "El juicio de ponderación y sus partes. Una crítica", en Alexy R. (coord.), Derechos sociales y ponderación, Fundación Coloquio Europeo, Madrid.

GuASTINI, RicCARDo, La “constitucionalización” del ordenamiento jurídico: el caso italiano, en Carbonell, M. (coord.), Neoconstitucionalismo(s), Trotta, Madrid,

Nino, Carlos Santiago, Ética y derechos humanos, Astrea, Buenos Aires, 1989.

Núñez Poblete, Manuel Antonio (2004). "Una introducción al constitucionalismo posmoderno y al pluralismo constitucional”, Revista Chilena de Derecho, Vol. $31 \mathrm{~N}^{\circ} 1$, pp. 115-136.

Olano García, Hernán Alejandro (Interpretación y neoconstitucionalismo), Porrúa e Instituto Mexicano de Derecho Procesal Constitucional, México, 2006,

Pozzolo, Susana, "Un constitucionalismo ambiguo", en Carbonell, M. (coord.), Neoconstitucionalismo(s), Trotta, Madrid, 2003.

Zagrebelsky, Gustavo, Historia y constitución, Trotta, Madrid, 2005. 